\title{
PAULO FREIRE E AS CRIANÇAS: UM CONVITE À INFÂNCIA
}

\author{
Marta Regina Paulo da Silva \\ Universidade Municipal de São Caetano do Sul (USCS), São Paulo, Brasil
}

\begin{abstract}
Resumo: Este ensaio propõe um diálogo com Paulo Freire e Ana Flávia, 4 anos, a respeito da escuta e do diálogo com as crianças e com a infância. Infância afirmada, neste trabalho, não como tempo cronológico vivido, mas como condição da própria existência humana. Inspirado na epistemologia inquieta e esperançosa de Freire, é um convite à infância e, com ela, à utopia e à esperança, que alimentam e reafirmam o compromisso ético e a luta por uma sociedade com justiça social e, portanto, com muito mais "boniteza".
\end{abstract}

Palavras-chave: Paulo Freire. Infância. Escuta. Participação Política.

“POSSO FALAR?"... UM INÍCIO, UM CONVITE...

Posso falar?

Eu sou uma criança! Sabe qual é o segredo das crianças? Brincar.

(Ana Flávia, 4 anos)

Somos constantemente interrogados(as) pela infância, a das crianças e a nossa. Com sua potência, a infância nos desenfeitiça, dando a ver um mundo de abertura e possibilidades onde até então era apenas reprodução, padronização, homogeneidade. Questiona nossas supostas certezas. Suspende o tempo cronológico, nos revelando um tempo de descontinuidades que nos impele a lugares inusitados, por vezes, conhecidos, mas pouco visitados. A infância, quando a escutamos, não nos deixa esquecer que é preciso sonhar, é preciso esperançar, é preciso brincar. A força transgressora da infância assusta, daí as várias estratégias de silenciá-la. É preciso calar a infância, amordaçá-la, subjugá-la. Ela ameaça. Ameaça, sobretudo, aqueles e aquelas que temem o sonho e a utopia de um outro mundo possível. A infância é utópica.

Neste ensaio, tocados(as) pela infância, propomos um diálogo com Paulo Freire, o menino conectivo, e as crianças. Convidamos então Ana Flávia, 4 anos, a se juntar a nós... Ou somos nós os(as) convidados(as) de Ana Flávia?... Ela, como toda criança, é perguntadeira (SILVA; FASANO, 2020), lança sobre nós a primeira pergunta. A pergunta inaugural. A pergunta convite: "Posso falar?".

A pergunta é clara e direta. Uma pergunta infantil que nos instiga a tantas outras: Será a pergunta de Ana Flávia um pedido de licença? Uma reivindicação? Uma denúncia? Talvez uma ironia? Pode não ser nada disso ou tudo isso. O fato é que seu questionamento nos remete a novas indagações. Afinal, quem tem direito à palavra em 
nossa sociedade? O que é a palavra? As crianças têm direito à palavra? Elas "podem falar"?

Ao percorrer a história da infância, reconhecemos uma trajetória de (in)visibilidade das múltiplas e diferentes infâncias de meninos e meninas. Suas histórias, escritas pelos(as) adultos(as), trazem a marca do silenciamento de suas vozes. Silêncio imposto por uma sociedade que compreendia e, em certa medida ainda, compreende a criança tão somente pela ausência ou por aquilo que ela é capaz de suprir: a criança como reprodutora de conhecimento e de cultura, como inocente, frágil, como natureza, cujos estágios de desenvolvimento são biologicamente determinados, a imatura; "como fator de suprimento do mercado de trabalho, que deve ser tratado para garantir um suprimento adequado de mão-de-obra e o uso eficiente dos recursos humanos" (DALBERG; MOSS; PENCE, 2003, p. 68, grifos dos autores), portanto, seres de pura adaptação ao mundo, que precisam ser moldados, disciplinados e silenciados.

Com Freire e Ana Flávia, defendemos outra compreensão da criança e da infância, que, longe de ser apenas uma etapa sucessiva do desenvolvimento humano, é uma "força revolucionária", potência criativa da vida em qualquer idade (KOHAN, 2020). Nosso desejo é que este diálogo seja um convite aos leitores e às leitoras, para pensarmos a criança e a infância e, com elas, reafirmar nosso compromisso ético e nossa luta por uma sociedade com justiça social e, portanto, com muito mais "boniteza".

\section{"EU SOU UMA CRIANÇA"!}

"Eu sou uma criança!". O que a afirmativa de Ana Flávia nos provoca? O que significa na voz de uma criança tal afirmação? Quem são as crianças? Seres de pura adaptação ou de intervenção no mundo?

Aqui, é preciso situar o contexto da fala de Ana Flávia. Um encontro entre educadores e educadoras da educação infantil no espaço da universidade, no qual discutia-se o trabalho com as crianças, tendo como foco suas linguagens e invencionices. Ana acompanhava a mãe, uma professora que participava do encontro, até que seu pai viesse buscá-la. O Grupo, em uma configuração circular, debate, e Ana, sentada em uma das carteiras, desenha. Durante a discussão, Ana se levanta, aproximase da educadora que coordenava o encontro e diz "Posso falar?", sendo imediatamente acolhida: "Claro"; "Eu sou uma criança! Sabe qual é o segredo das crianças?" (não houve tempo para a resposta) "Brincar". Virou-se e voltou ao seu desenho.

Ana Flávia e as crianças de todas as idades não são seres de pura adaptação, seres passivos diante das realidades que as circundam. Como ser inacabado e inconcluso, Ana, assim como todos e todas nós, está em permanente processo de busca do "ser mais". Essa condição nos coloca no e com o mundo de forma curiosa, inquieta, o que nos leva a intervir nele nos constituindo como seres históricos e culturais (FREIRE, $\left.1997[1996]^{1}\right)$.

Meninos e meninas leem e comunicam o mundo desde que nascem, através de suas múltiplas linguagens. A curiosidade é fundante nesse processo para que possam aprender e apreender o mundo, o ressignificando. A curiosidade, como assevera Freire 
SILVA, M. R. P. da.

(1997 [1996]), já é, em si, conhecimento, assim como a linguagem, que, para esse educador, não é apenas a expressão do conhecimento, mas também conhecimento.

Retornando à cena com Ana Flávia, podemos identificar a potência de sua fala. Discutíamos sobre as crianças, sua educação, suas linguagens. E quem melhor que ela, a criança, para nos ensinar sobre "seus segredos"? Freire (1993, p. 98), em sua obra Professora sim, tia não, convoca-nos a conhecer as crianças: "As educadoras precisam saber o que se passa no mundo das crianças com quem trabalham. O universo de seus sonhos, a linguagem com que se defendem, manhosamente, da agressividade de seu mundo. O que sabem e como sabem independentemente da escola".

Conhecer as crianças para além dos muros da escola nos permite conhecer suas (r)existências, desconstruindo imagens negativas sobre elas e reconhecendo-as como seres potentes. Nesse sentido, é preciso, como propõe Malaguzzi (1999, p. 76), que deixemos "verdadeiramente para trás uma visão da criança como egocêntrica, focalizada apenas na cognição e nos objetos físicos, cujos sentimentos e afetividade são subestimados e menosprezados".

"Eu sou uma criança" é a afirmação dessa potência, dessa força, dessa identidade e desse pertencimento a um grupo social, o das crianças, grupo historicamente excluído de seu direito à palavra, ao exercício do seu direito político de participação nas decisões que dizem respeito à sua vida. Freire (2001 [1959]), já em Educação e Atualidade Brasileira, final da década de 1950, denunciava as relações autoritárias e antidialógicas presentes nas relações da família, escola e sociedade para com as crianças. Defendia a urgência de se rever essas relações verticalizadas, de modo a construir relações mais dialógicas com os meninos e as meninas, afirmando-os(as) como sujeitos de sua própria vida.

Essa defesa da escuta e do diálogo com as crianças apresenta-se em outras obras desse educador, demonstrando sua preocupação também com as crianças e sua educação. Em suas palavras, "Interessou-nos sempre e desde logo, a experiência democrática através da educação. Educação da criança e do adulto" (FREIRE, 2001 [1959], p. 14).

Percorrendo sua obra, identificamos a compreensão da criança como sujeito político, com direitos que precisam ser assegurados, dentre eles o da participação. Contudo, sabemos que o controle dos espaços sociais das crianças pelos(as) adultos(as) produziu uma compreensão de que elas estão " «naturalmente» privadas do exercício de direitos políticos" (SARMENTO; FERNANDES; TOMÁS, 2007, p. 184), o que inviabiliza reconhecê-las como "atores políticos concretos".

Importante ressaltar que a defesa da participação das crianças está intrinsicamente relacionada à defesa do direito à provisão e à proteção. Esses três direitos são indissociáveis e precisam ser considerados quando pensamos e defendemos a cidadania das crianças. Como alerta Freire (2001 [1993], p. 26), é preciso que ocorra "sem que isto signifique correr o risco de ser discriminado, punido ou, pior ainda, banido da vida"

A afirmativa potente de Ana Flávia nos interroga sobre nossas próprias concepções de criança e de infância e como as acolhemos em nossas instituições, em nossas vidas. Aprisionar as crianças e a infância em uma única definição é uma tarefa impossível e desnecessária, mais potente nos parece pensá-las em sua alteridade, em seu direito político de dizer a sua palavra, de ler e inteligir o mundo desde as suas 
múltiplas linguagens, de participar das decisões referentes aos espaços sociais que ocupam, de brincar, de sonhar e de continuar a nos interrogar e nos inquietar. Afinal, sabemos quais são os seus segredos?

\section{"SABE QUAL É O SEGREDO DAS CRIANÇAS?"}

Ana Flávia continua a nos interrogar: "Sabe qual é o segredo das crianças?". Sabemos? Escutamos? Escutamos as crianças? Se as escutamos, o que fazemos com essa escuta?

Escutar a pergunta de Ana Flávia e com ela dialogar implica reconhecê-la como um ser de intervenção no mundo, portanto, curiosa, perguntadeira, cidadã. Exige afirmar o diálogo, como aprendemos com Freire (2003 [1970]), como uma "exigência existencial", uma vez que, ler e dizer o mundo é direito de todos e todas, inclusive das crianças.

O diálogo solicita de nós que acreditemos na potência de meninos e meninas e na relação de interdependência que existe entre nós, pois, se é verdade que as crianças dependem de nós, é igualmente verdadeiro que nós também dependemos delas, e da infância, para continuarmos nos fazendo humanos. Por isso, talvez, Paulo Freire se define como um "menino conectivo", além de alertar para que jamais deixemos morrer em nós o menino ou a menina que fomos.

Ao longo de sua vida educadora, em vários momentos, Freire relatou sua infância; não de forma saudosista, mas em um rico movimento de reflexão sobre o vivido, "um ato de curiosidade necessário" (FREIRE, 2003 [1994], p. 38), para a compreensão do "menino de ontem" e a atividade educativa, política, do "homem de hoje". Nessas incursões pela infância, compreende-se um menino em conjunção, em conexão entre distintas classes sociais:

A minha experiência de menino, a que me refiro dizendo que eu fui um menino conectivo, quer dizer uma espécie de conjunção entre os meninos de classe média (como eu) e os meninos camponeses, obreiros urbanos, que foram meus companheiros. Eu ligava uns aos outros (FREIRE, 2000, p. 281-282).

A autodenominação "menino conectivo" entrelaça duas ideias: a infância e a conectividade. Para Mafra (2020, p. 50-51, grifos do autor), refere-se a um "encontro da conectividade consciente do adulto com a liberdade do menino. [...] Nesse entendimento, Freire se traduz como um ser de ligação, na racionalidade do adulto, e de abertura, na ingenuidade e na inconclusão do menino". O fio condutor é a própria liberdade do menino, que se reafirma no(a) adulto(a) em liberdade/libertação, conceitos indissociáveis na epistemologia freiriana, visto que a conquista da liberdade implica a luta pela libertação não apenas de si, mas também do(a) outro(a) e na transformação do mundo (FREIRE, 2003 [1970]).

Podemos inferir que a conectividade com a infância nos coloca em permanente processo de curiosidade e abertura no e com o mundo. O que nos remete a pensá-la não 
SILVA, M. R. P. da.

somente como uma etapa cronológica da vida, mas como uma condição da própria existência humana (SANTOS NETO; SILVA, 2006). Um eterno "meninizar-se".

Em carta a sua prima Nathercia, na época com 9 anos de idade, Freire pondera:

É uma coisa boa, Natercinha, que a gente nunca deixe de ser menino. Os homens atrapalham as coisas, complicam tudo. Não sei se você vai entender isso que vou lhe dizer. Mamãe e papai the explicam melhor. Cresça, mas nunca deixe morrer em você a Natercinha de hoje, que começa a descobrir o mundo, cheia de curiosidade. Se os homens não deixassem morrer dentro deles o menino que eles foram, se compreenderiam melhor (FREIRE apud LACERDA, 2016, p. 50).

A infância rompe com a adultez que, sisuda, já não consegue mais sonhar, criar, brincar, esperançar. Como potência criadora, ela nos convida ao estranhamento, à imaginação, à criação, ao encantamento. Convoca-nos a estranhar o que, já familiarizado, se cristalizou em nossas vidas, em nossas instituições, em nossas relações.

Dialogar com Ana Flávia, e com todas as crianças, é permitir-se a esse encontro infantil, de seres que, em comunhão e mediatizados pelo mundo, o interrogam na perspectiva de construir realidades que se afirmem mais gentis e justas com todos os seres que habitam o planeta. Esse diálogo reconhece o direito de todos e todas de serem autores e autoras de suas próprias vidas, o que implica em um profundo respeito e compromisso consigo, com o(a) outro(a) e com a Terra.

Eis aqui o fundamento do diálogo, a amorosidade como radicalidade de uma exigência ética. É preciso fazer o mundo mais bonito, defende Freire (1997 [1996]; 2000). Acreditar e lutar para a "[...] criação de um mundo em que seja menos difícil amar" (FREIRE, 2003 [1970], p. 184). Um mundo que não aceitará a naturalização da morte (extermínio) de "outros sujeitos", grupos sociais que "[...] carregam as desigualdades porque como diferentes em etnia, raça, classe são inferiores. Nasceram desiguais, inferiores, sub-humanos. Uma condição de origem" (ARROYO, 2014, p. 123).

Mbembe (2017) alerta-nos sobre a "necropolítica", a política de morte que impera em nossa sociedade, ou seja, a decisão do Estado sobre quem pode viver e quem pode morrer. Nesse contexto, o exercício da soberania é, segundo o autor, "a capacidade de definir quem importa e quem não importa, quem é 'descartável' e quem não é". (MBEMBE, 2017, p. 135). Em que lugar se encontram as crianças nesse contexto? Nessa política? Quais crianças devem viver e quais devem morrer?

A afirmativa de Ana Flávia ecoa mais forte "Eu sou uma criança". Como criança, deve ter assegurados os seus direitos de participação, provisão e proteção. Pensando nesse contexto de barbárie em que vivemos, onde estão as crianças? Como estão vivendo suas infâncias nesse contexto pandêmico? Estão elas protegidas não apenas do vírus, mas das inúmeras violências sofridas em função de sua classe social, idade, gênero, raça, etnia, orientação sexual e outros tantos marcadores sociais?

Pensar certo, como defende Freire (1997 [1996], p. 39-40), implica na rejeição a qualquer forma de discriminação, pois "a prática preconceituosa de raça, de classe, de gênero ofende a substantividade do ser humano e nega radicalmente a democracia". $O$ que dizer de uma sociedade cuja economia se impõe em detrimento à vida? O vírus, 
como temos acompanhado através das mídias, não distingue quem irá se contaminar, no entanto, as ações da sociedade e do Estado fomentam dinâmicas de diferenciação, tornando mais vulneráveis à Covid-19 aqueles e aquelas que se encontram em condições mais precárias de existência (MOURA; SILVA, 2021).

A afirmação de seu pertencimento à categoria "criança" evoca, através do posicionamento de Ana Flávia, a complexidade que envolve a criança e a infância, e nos convoca à escuta de suas vozes. Escuta que só pode ser aprendida no exercício amoroso do diálogo com elas.

\section{O SEGREDO DAS CRIANÇAS: "BRINCAR"}

A interrogação de Ana Flávia ainda nos acompanha. Ela demonstra querer compartilhar conosco "o segredo" de seu grupo geracional. Um ato de confiança em nós, adultos(as)? O desejo de dialogar? Uma desconfiança em face à nossa capacidade de compreender que o brincar é sua linguagem? Por que o brincar, apesar de tantos estudos e pesquisas, se apresenta, na fala desta criança, como um segredo? Já não sabíamos desse segredo?

Freire (1997 [1996]), em vários momentos de sua vida educadora, pontuou a necessidade da busca da coerência entre o pensar e o agir, entre o discurso e a prática. $\mathrm{O}$ discurso da criança potente, como se observa hoje inclusive em alguns documentos legais, apresenta-se, ainda, na maioria das instituições educacionais, muito distante dos contextos educativos preparados para ela. Contextos preparados para e não com ela. Contextos ainda marcados pelo modelo escolar hegemônico, que prima pela reprodução, o silêncio dos corpos e a padronização.

Em sua principal obra, Pedagogia do Oprimido, Freire (2003 [1970]) faz referência às crianças justamente no capítulo em que analisa a "invasão cultural", sendo esta uma ação antidialógica imposta pelo opressor. $\mathrm{O}$ autor demonstra tratar-se não apenas de uma forma de dominação econômica, mas cultural, que nega àquele(a) que é dominado(a) o direito de dizer a sua palavra, ao mesmo tempo em que desqualifica a sua cultura.

A invasão cultural ocorre entre os diferentes atores sociais e de diferentes formas. No caso das crianças, afirma-se no adultocentrismo, com ações antidialógicas e autoritárias que, subestimando a capacidade de criação e recriação de meninos e meninas, procura afogar neles e nelas o desejo de curiosa, criativa e coletivamente, aventurarem-se no conhecimento do mundo, físico e social. Daí, compreendê-los(as) tão somente como reprodutores(as) da cultura, cabendo aos(às) adultos(as) prepará-los(as) para a vida em sociedade.

Como uma forma de "domesticação", que intenta uma atitude de sujeição a uma determinada ordem social, a invasão cultural defronta-se com as transgressões e resistências das crianças que, ao interrogarem nossos saberes, fazeres e os currículos, denunciam a "fôrma escolar" das instituições educacionais historicamente construídas para elas, com práticas autoritárias e antidialógicas. Para Freire renunciar à invasão 
SILVA, M. R. P. da.

cultural significa "deixar de estar sobre ou 'dentro', como 'estrangeiros', para estar com, como companheiros" (FREIRE, 2003 [1970], p. 154, grifos do autor).

Renunciar o adultocentrismo que ainda impera em nossas instituições implica desconstruir a cultura do silêncio que se impôs sobre as vozes infantis, legitimando seu lugar na sociedade como cidadãs, atores sociais e políticos com direito à participação. Concordando com Tonucci, (2005, p. 18), se assim for "a relação com elas será correta, entre cidadãos adultos e pequenos cidadãos, mas, agora, cidadãos".

Escutar as crianças significa nos silenciar, sem com isso deixarmos de dizer a nossa palavra. Configura-se não como abandono ou omissão, mas um profundo respeito à capacidade dos meninos e das meninas de pensar e agir no mundo:

O silêncio possibilita escutar, com olhos e ouvidos atentos, seus gestos, seus olhares, suas expressões, seus movimentos, seus desejos, seus interesses, de modo a estabelecer um diálogo que tem como marca, não apenas a palavra verbalizada, mas todas as formas de expressão pelas quais as crianças dizem o mundo (SILVA, 2017, p. 92).

A escuta é, portanto, disponibilidade ao(à) outro(a). É uma atitude. Implica em respeito às diferenças, sem o qual não é possível escutar. Escutar meninos e meninas é abrir-se à suas leituras de mundo, às suas histórias, é aventurar-se com eles e elas na construção do conhecimento, é legitimar suas vozes (VICENTE; SILVA, 2020).

Ana Flávia explicita o "segredo das crianças": brincar. Ao mesmo tempo em que explicita nossas fragilidades, a nossa incapacidade de legitimar, na prática e não apenas no discurso, a brincadeira como a atividade central de suas vidas. Ela revela o brincar como o segredo das crianças, portanto, como algo que nós, adultos(as), ainda não compreendemos ou insistimos em não compreender. Talvez nos falte, como ajuíza Freire (FREIRE; GUIMARÃES, 1984), a coragem de deixarmos voar a imaginação com as crianças. Nas palavras do educador:

Acho que o que falta, a muitos de nós, educadores, e a mim também, é imaginação. A gente tem medo de deixar a imaginação voar, mas é preciso deixá-la voar! Não voar a ponto de se perder, mas voar, imaginar coisas concretas, coisas possíveis, com as crianças (FREIRE; GUIMARÃES, 1984, p. 45).

A escuta é receptiva, aberta, inquieta. Sendo assim, está mais próxima das linguagens das perguntas do que das respostas. Escutar as crianças é compreender, como assevera Faundez:

[...] que a linguagem é de natureza gestual, corporal, é uma linguagem de movimento de olhos, de movimento do coração. A primeira linguagem é a do corpo e, na medida em que essa é uma linguagem de perguntas e na medida em que limitamos essas perguntas e não ouvimos ou valorizamos senão o que é oral ou escrito, estamos eliminando grande parte da linguagem humana. Creio ser fundamental que o professor valorize em toda sua dimensão o que constitui a linguagem, ou as linguagens, que são 
linguagens de perguntas antes de serem linguagens de respostas (FREIRE; FAUNDEZ, 2017 [1985], p. 71).

As respostas cerram a passagem, apenas as perguntas nos convidam a passar, a continuar caminhando, a conhecer. Que possamos ser instigados(as) com as perguntas das crianças ao mesmo tempo em que possamos instigá-las a continuar perguntando, reconhecendo o ato de pensar como investigação, como um aventurar-se.

\section{E POR FIM... BRINCAR, O SEGREDO DAS CRIANÇAS}

Neste ensaio, com Ana Flávia e Paulo Freire, refletimos acerca da potência da infância: das crianças e da nossa. Uma infância que não termina passado certo período cronológico, mas que nos acompanha por toda a vida. Uma infância potente e criativa, além de curiosa e inquieta. Que nos coloca em movimento, que rompe com a sisudez da adultez, que sonha e brinca.

Ana Flávia nos apresentou o segredo. De posse dele, que possamos brincar, nos alegrar e jamais perder a capacidade de se espantar. Como sujeitos brincantes, que repudiemos toda e qualquer forma de ameaça à dignidade humana e que, coletivamente indignados(as), lutemos contra a "malvadez" que subjuga e mata os grupos sociais mais vulneráveis.

Como seres brincantes e, por isso mesmo, com profunda seriedade, façamos do sonho, da esperança e da utopia nossas armas. Utopia que se afirma hoje, mais do que nunca, como uma necessidade de pensar, no coletivo, o impensável, de romper com as diferentes formas de exclusões (SANTOS, 2018). Esperança que, como nos ensina Freire, não é pura espera, mas "condimento indispensável à experiência histórica" (FREIRE, 1997 [1996], p. 81), sendo parte constitutiva da natureza humana.

Artigo recebido em: 01/04/2021

Aprovado para publicação em: 29/06/2021

\section{PAULO FREIRE AND CHILDREN: AN INVITATION TO CHILDHOOD}

ABSTRACT: This essay proposes a dialogue with Paulo Freire and Ana Flávia, 4 years old, about listening and dialogue with children and childhood. Childhood affirmed in this work not as a chronological time lived, but as a condition of human existence itself. Inspired by Freire's restless and hopeful epistemology, it is an invitation to childhood, and with it the utopia and hope that nourish and reaffirm the ethical commitment and the struggle for a society with social justice and, therefore, with much more "boniteza".

KEYWORDS: Paulo Freire. Childhood. Listening. Political Participation. 
PAULO FREIRE Y LA INFANCIA: UNA INVITACIÓN A LA INFANCIA

RESUMEN: Este ensayo propone un diálogo con Paulo Freire y Ana Flávia, de 4 años, sobre la escucha y el diálogo con los niños y la infancia. La infancia afirmada en esta obra no como un tiempo cronológico vivido, sino como una condición de la existencia humana misma. Inspirada en la epistemología inquieta y esperanzada de Freire, es una invitación a la infancia, y con ella a la utopía y la esperanza que nutren y reafirman el compromiso ético y la lucha por una sociedad con justicia social y, por tanto, con mucho más "boniteza".

PALABRAS CLAVE: Paulo Freire. Infancia. Escuchando. Participación Politica.

NOTA

Nas citações das obras de Paulo Freire, seguida da data da edição utilizada neste trabalho, encontra-se, entre colchetes, a data da $1^{a}$ edição, a fim de considerar o período em que suas ideias foram desenvolvidas. Quando estas coincidiram, esse recurso não foi utilizado.

\section{REFERÊNCIAS}

ARROYO, M. G. Outros sujeitos, outras pedagogias. 2 ed. Petrópolis, RJ: Vozes, 2014.

DAHLBERG, G.; MOSS, P.; PENCE, A. Qualidade na Educação da Primeira Infância: perspectivas pós-modernas. Porto Alegre: Artmed, 2003.

FREIRE, P. Cartas a Cristina: reflexões sobre minha vida e minha práxis. 2. ed. rev. São Paulo: Paz e Terra, 2003 [1994].

FREIRE, P. Diálogo com o educador Paulo Freire. In: VENTORIM, S. (org.). Paulo Freire: a práxis político-pedagógica do educador. Vitória: Edufes, 2000, p. 273-298.

FREIRE, P. Educação e atualidade brasileira. São Paulo: Cortez/IPF, 2001 [1959].

FREIRE, P. Pedagogia da autonomia: saberes necessários à prática educativa. 5. ed., Coleção leitura. São Paulo: Paz e Terra, 1997 [1996].

FREIRE, P. Pedagogia do oprimido. 35. ed. Rio de Janeiro: Paz e Terra, 2003 [1970].

FREIRE, P. Política e educação. 6. ed. Coleção Questões da Nossa Época, v. 23. São Paulo: Cortez, 2001 [1993]. 
FREIRE, P. Professora sim, tia não: cartas a quem ousa ensinar. São Paulo: Olho d'Água, 1993.

FREIRE, P.; GUIMARÃES, S. Sobre a Educação: diálogos. v. 2. Rio de Janeiro: Paz e Terra, 1984.

FREIRE, P; FAUNDEZ, A. Por uma pedagogia da pergunta. 8.ed. Rio de Janeiro / São Paulo: Paz e Terra, 2017 [1985].

KOHAN, W. O. Paulo Freire e a (sua) infância educadora. Im. SILVA, M. R. P. da; MAFRA, J. F. (org.). Paulo Freire e a educação das crianças. São Paulo: BT Acadêmica, 2020, p. 83100.

LACERDA, N. A casa e o mundo lá fora: cartas de Paulo Freire para Nathercinha. Rio de Janeiro: Zit, 2016.

MAFRA, J. F. O menino conectivo: a infância como ontologia do ser social em Paulo Freire. In: SILVA, M. R. P.; MAFRA, J. F. (org.). Paulo Freire e a educação das crianças. São Paulo, Brasil: BT Acadêmica, 2020, p. 29-56.

MALAGUZZI, L. Histórias, ideias e filosofia básica. In: EDWARDS, C.; GANDINI, L.; FORMAN, G. As cem linguagens da criança: a abordagem de Reggio Emília na educação da primeira infância. Porto Alegre: Editora Artes Médicas Sul, 1999. p. 59-104.

MBEMBE, A. Necropolítica: biopoder, soberania, estado de exceção política da morte. Revista Arte \& Ensaio, p. 123-151, 2017. Disponível em: <https://www.procomum.org/wp-content/uploads/2019/04/necropolitica.pdf $>$. Acesso em: 15 fev. 2021.

MOURA, M. de A de; SILVA, M. R. P. da. Crianças em situação de acolhimento institucional e o ensino remoto: um olhar desde a epistemologia freiriana. Revista Estudos Aplicados em Educação, São Caetano do Sul, v. 6, n. 11, 2021, p. 37-49. Disponível em: <https://seer.uscs.edu.br/index.php/revista_estudos_aplicados/article/view/7784/3393>

. Acesso em: 10 ago. 2021.

SANTOS NETO, E. dos; SILVA, M. R. P. da. Infância e inacabamento: um encontro entre Paulo Freire e Giorgio Agamben. 2006, p. 1-13. Disponível em: $<$ https://egov.ufsc.br/portal/conteudo/inf\%C3\%A2ncia-e-inacabamento-um-encontroentre-paulo-freire-e-giorgio-agamben>. Acesso em: 13 jun. 2020.

SANTOS, B. de S. É necessário ser utópico hoje? In: SANTOS, Boaventura de S. Na oficina do sociólogo artesão: aulas 2011 a 2016. São Paulo: Cortez, 2018, p. 321-343. 
SILVA, M. R. P. da.

SARMENTO, M. J.; FERNANDES, N.; TOMÁS C. Políticas públicas e participação infantil. Educação, Sociedade \& Culturas, Porto, n. 25, 2007, 183-206. Disponível em: $<$ https://www.fpce.up.pt/ciie/revistaesc/ESC25/ManuelJacintoSarmento.pdf $>$. Acesso em 15 fev. 2021.

SILVA, M. R. P. da. Por uma educação infantil emancipatória: a vez e a voz das crianças e de suas professoras. Cadernos de Educação, Pelotas, 2017, p. 83-100. Disponível em $<$ https://periodicos.ufpel.edu.br/ojs2/index.php/caduc/article/view/12370 $>$. Acesso em: 15 fev. 2021.

SILVA, M. R. P. da; Fasano, E. Crianças e infâncias em Paulo Freire. In: SILVA, M. R. P.; MAFRA, J. F. (org.). Paulo Freire e a educação das crianças. São Paulo: BT Acadêmica, 2020, p. 57-82.

TONUCCI, Francesco. Quando as crianças dizem: agora chega! Porto Alegre: Artmed, 2005.

VICENTE, A. de J.; SILVA, M. R. P. da. A participação política das crianças pequenas na autoavaliação da qualidade da educação infantil: contribuições desde Paulo Freire. Educação \& Linguagem, São Bernardo do Campo, v. 23, n. 2, p. 203-224, jul.-dez., 2020. Disponível em: <https://www.metodista.br/revistas/revistasmetodista/index.php/EL/article/view/10435/7425>. Acesso em: 20 maio 2021.

Marta Regina Paulo da Silva: Doutora em Educação pela UNICAMP. Mestra em Educação pela Universidade Metodista de São Paulo. Graduada em Psicologia e Pedagogia. Docente-Pesquisadora do Programa de Pós-Graduação em Educação da Universidade Municipal de São Caetano do Sul. Líder do Grupo de Estudos e Pesquisa Infâncias, Diversidade e Educação - GEPIDE (PPGE/USCS). Coordenadora do Grupo de Estudos e Pesquisa Paulo Freire - GEPPF (PPGE/USCS).

Orcid: https://orcid.org/0000-0002-8574-760X

E-mail:martarps@uol.com.br

Este periódico utiliza a licença Creative Commons Attribution 3.0, para periódicos de acesso aberto (Open Archives Initiative - OAI). 